\title{
Home discharge and management in severe DBP patient
}

\author{
Patrizio Fiorini \\ From XXI Congress of the Italian Society of Neonatology \\ Palermo, Italy. 24-26 September 2015
}

Bronchopumonary dysplasia( DBP) is the most common sequelae related to very low birth weight, has a multifactorial aetiology and first characterized by Northway(1967), now unlike the original form of the disease, new form often develops in preterm newborns who may have needed little or no ventilator support, and have had low inspired oxygen concentration during early postnatal days. "New" DBP affects newborn with gestational age very low, could be the result of impaired lung growth (impaired alveolar or vascular growth). Affects about $68 \%$ of newborn between 22 and 26 gestational weeks and about $25 \%$ of newborn weight $>1500 \mathrm{gr}$. New DBP is defined as oxygen dependence for at least 28 days after birth, depending on the degree of respiratory support at 36 weeks of postnatal age or at the discharge, the disease is classified as mild, moderate or severe. Home discharge of patient with severe DBP is considered if the following criteria are fulfilled: a- sustained weight gain for a long time; b-maintains a normal body temperature fully clothed in an open bed; c- shows competent suckle feeding without cardiorespiratory compromise; $d$ - has not had a relevant apnea, bradycardia, or oxygen desaturation for at least five days prior to discharge; e- demonstration of parental competence in all aspect of infant care; $f$ - parental participation in a postnatal care program. Prior to discharge the parents are taught home resuscitation on the neonatal unit. They also receive a visit from the home oxygen nurse who discusses and gives training to the parents in the use of home oxygen. The equipment for domiciliary oxygen is a liquid oxygen system (pressurize gas cylinders, concentrators) comprising a storage vessel and a small portable vessel which can easily filled. The oxygen is supplied with a lowflow-meter via mono or binasal canula. A pulse oxymeter is prescribed to monitor $\mathrm{SaO} 2$ and cardiac frequency. Optimal $\mathrm{SaO} 2$ targets have to be further investigated by

Correspondence: patrizio.fiorini@meyer.it

Neonatal Intensive Care AOU Meyer Firenze, Italy controlled studies but actually is $>93 \%$. One the most challenging aspects of the treatment of DBP is the management of ventilator assisted children and tracheostomy in the home. Caregivers are trained in emergency procedures including CPR, tracheostomy changes and manual ventilator. Maintenance of oxygenation and proper nutritional support are critical aspects in the post-discharge management of these infants as immunization and neurodevelopmental follow-up.

Published: 24 September 2015

\section{References}

1. Balfour-Lynn I M, Field D J, et al: Thorax 2009, 64(supl II).

2. Adde V.Fabiola, Alvarez EAlfonso, barbisan Nbeatriz, Guimares Rbianca: Jornal de Peditria 2013, 89:6-17.

3. Thomas Wolfang, Speer PChristian: Early Human Development 2005, 81:155-163.

4. Mazloum Dania el, Moschino IL, bozzetto S, baraldi E: Neonatology 2014, 105:352-356.

5. Shaw NJ, Kotecha Sailesh: Early Human Development 2005, 81:165-170.

6. Luna Sanchez M, Hernando Moreno J, et al: Anales de Pediatria 2013, 79(4):262-6.

7. Tarazona Perez S, Esteban Rueda S, et al: Anales de Pediatria 2015, 1-9.

doi:10.1186/1824-7288-41-S1-A11

Cite this article as: Fiorini: Home discharge and management in severe DBP patient. Italian Journal of Pediatrics 2015 41(Suppl 1):A11.

Submit your next manuscript to BioMed Central and take full advantage of:

- Convenient online submission

- Thorough peer review

- No space constraints or color figure charges

- Immediate publication on acceptance

- Inclusion in PubMed, CAS, Scopus and Google Scholar

- Research which is freely available for redistribution 